\title{
Diversity Management Change Projects: In Need of Alternative Conceptual Approaches?
}

\author{
Christina Evans', Judith Glover²
}

\begin{abstract}
Drawing on a meta-analysis of an evaluation of a European Social Fund project aimed at enhancing employment opportunities for women in Information Technology, Electronic and Computing (ITEC), this paper critically debates how effectual a diversity management approach alone is as an underpinning rationale for change in the complex area of diversity. The paper draws on the experiences of 'partner organizations', gathered through interviews conducted during the evaluation stage of the project. The paper discusses some of the tensions experienced by partner organizations, thus providing new insights into why such projects are not as effectual as they might be. The paper concludes by presenting a case for the need to re-conceptualise how change as part of a wider diversity management approach might best be conceptualized. We suggest that a 'systems approach' could prove a more fruitful way of conceptualizing change of this nature given the interdependences between different organizations and institutions.
\end{abstract}

Keywords: gender diversity; ITEC employment; organizational change; systems approach.

\footnotetext{
'University of Roehampton London Business School. Christina is a Principal Lecturer in the Business School. She has published a number of papers and reports on women's employment in the ICT sector. Her other research interests include the changing nature of individual and organizational careers. Address: Southlands College, 80 Roehampton Lane, London SWI5 5SL Email: c.evans@roehampton.ac.uk Tel: $+44(0) 2083923218$.

'University of Roehampton London Business School. Judith is Emeritus Professor of Employment Studies in the Business School. Her research interests include women's employment, particularly women in scientific employment. She has published widely in this area. Current research interests include 'hybrid' jobs in IT - jobs that combine technical and 'soft' skills. Judith is on the European Commission's list of experts on specific science and technology policy issues. Address: Southlands College, 80 Roehampton Lane, London SWI5 5SL Email: j.glover@roehampton.ac.uk
}

ISSN: 07 I8-2724. (http://www.jotmi.org)

Journal of Technology Management \& Innovation (C) Universidad Alberto Hurtado, Facultad de Economía y Negocios. 


\section{Introduction}

\section{Diversity management as a rational approach to organizational competitiveness?}

With the growing economic importance of the knowledge and service sector, and the reported increased competition for scarce resources (e.g. talented employees), diversity management has emerged as a key managerial discourse and practice. Pursing a diversity management approach could be considered a rational response to conducting business in a competitive global labour market: hence the unquestioned adoption of generic diversity 'business case' arguments including enhanced recruitment and retention of scare talent and improved creativity and innovation through access to different perspectives and voices (Marvin and Girling, 2000; Kersten, 2000; DTI, 2005). Diversity management, as will be discussed later, could be considered a paradigmatic shift in the way that equality and diversity is conceptualized. Rather than drawing on complex legal, or moral arguments, the discourse of diversity management draws on more positive transformational discourse, emphasising the positive benefits to organizational cultures and individuals. It is assumed that change initiated under the auspices of a diversity management approach is thus more likely to be welcomed by managers (Glover and Kirton, 2006).

The overall aim of this paper is to critically discuss the way that change initiated under the auspice of diversity management is conceptualized and hence enacted. It draws on a case of a large ESF funded change project that involved a number of partner organizations that came together to promote and change the employment and career opportunities, particularly for women, within the broad field of ITEC. The wider context for this particular ESF project, and this paper, is the declining representation of women in Information Technology, Electronic and Computing (ITEC) employment, despite the reported shortage of skilled workers in this sector (Lanvan and Passman, 2008; Glover and Guerrier, 2010; Valenduc, 20I I; e-skills, 20I I): a situation where it could be conceived that adopting a diversity management approach would be an appropriate strategy. The paper presents the tensions and frustrations associated with diversity change initiatives that arguably fall within a diversity management approach, viewed through the lens of the different partner organizations.

The rest of this paper is structured as follows. First, we introduce contemporary debates in the field of diversity management focusing on the perspective that diversity management is an organizational responsibility and thus can be conceptualized as an organizational change project. In particular we question whether the change strategies typically associated with a diversity management approach are effectual, given the complexities of bringing about diversity change. Second, the overall project on which our evaluation study was based, together with our involvement, is introduced to provide a context for the findings section. Third, we then present the findings which set out and discuss a number of tensions and frustrations experienced by the different stakeholders involved in this specific ESF diversity change project: these are presented to support our overall argument that a diversity management approach on its own is insufficient to address issues of gender diversity in the workplace (in this case in ITEC workplaces). Finally, the paper concludes by presenting a case for the need to re-conceptualise how diversity change, that realistically no single organization can address in isolation, can best be enacted. The authors suggest that adopting a systems approach could perhaps offer a more fruitful way of conceptualizing diversity change, thus helping expose the limitations of prescriptive 'best practice' change approaches that dominate much of the diversity management practitioner literature in particular.

\section{Diversity management and relationship with organizational change}

Diversity management emerged as a concept from the US following the Workforce 2000 report (Johnston and Packer, 1987) which drew attention to significant changes in the demographics of the US workforce and thus the implications for business. The interest in diversity management has spread in recent years and has become a key managerial response to changing economic and social factors perceived as having an effect on organizational competitiveness. As Healy et al. (20I I) point out diversity management, with its associated practice of 'business case' arguments, have been construed as "... a rational response to a competitive labour market." (pI0).

For practitioners engaged in diversity change the shifting discourse to economic 'business case' language, now widely associated with a diversity management approach, has provided a key lever from which to initiate change. This shifting discourse is assumed to be more understandable and appealing to managers, as well as a closer fit with the discourse and practices associated with Human Resource Management (see Foster and Harris, 2005; Glover and Kirton, 2008; Ashley, 20I0). Oswick (20lI) suggests that there is an inherent sense of novelty and newness in this shifting discourse, which could further explain why managers find it so appealing. Perhaps this is part of the attractiveness: it can give the illusion of change, even where it is difficult to find substantive evidence of actual change. But as Healy et al. (20I I) argue, just because the discourse surrounding diversity is changing, this doesn't necessarily mean that organization's commitment to bringing about change is any different. Diversity management, as an organizational responsibility is 
thus inevitably voluntarist ( $\mathrm{Ng}$ and Burke, 2005; Greene and Kirton, 2009): organizations can choose what diversity initiatives to champion and when, to meet their own specific business needs. An example here, as Abir-Am (2010) points out, relates to organizations' approach to flexible working: something that is more likely to be offered in specific technology fields particularly where there is a requirement for a continuing supply of new talent to ensure innovation. This in adopting a 'business case' rationale organizations invariably prioritize initiatives aimed at solving short-term business problems, rather than demonstrating a commitment to resolving wider diversity goals (Dickens, 1999; Dick and Nadin, 2006; Bleijenbergh et al., 2010). Hence the claims of organizations being more likely to adopt a 'pet projects' (Dass and Parker, 1999), 'best guesses' (Kalev et al., 2006) or 'pick-andmix' approach (Ozbilgin and Tatli, 2008) to diversity change The practitioner literature in particular has been criticized for promoting prescriptive 'best practice' diversity initiatives that frequently involve changes directed at helping individuals to change, as opposed to addressing structural inequalities and accountabilities (Kersten, 2000; Griffiths and Moore, 2006; $\mathrm{Ng}, 2008$ ). The transformational agenda, assumed to be a key goal of a diversity management approach, somehow getting lost due to the focus on short-term organizational outcomes.

Yet despite the promotion and adoption of prescriptive 'best practice' change approaches, there is no consensus as to what specific ingredients (or conditions) are required. Effective support from senior management, specifically Chief Executives, is invariably positioned as crucial (Kochan et al, 2003; $\mathrm{Ng}, 2008$ ). Other structural aspects are considered important too, for example, establishing a Diversity Office, as well as appointing Diversity Officers with overarching responsibility for initiating and championing change. Where the Diversity Office sits within an organization's formal structure would appear to be significant too in terms of its perceived power base and implications from an organizational learning perspective (Ozbilgin and Tatli, 2008). Although the Diversity Office and Diversity Officers represent a key part of the formal structures through which diversity change is initiated, others (e.g. line managers, employees) can be influential in initiating change too. Moreover, diversity change can be initiated and championed through informal structures and networks, located within, or outside, an organization (Healy et al, 20I I;Avdelidu-Fischer, 20I I).

\section{Alternative ways of conceptualizing diversity change: a systems approach?}

As the discussion above indicates, the way that change associated with a diversity management approach is conceived and positioned has been contested. Drawing on the work of Huy (200I), Tatli and Ozbilgin (2009) point out issues with frag- mented literature, lacking in theoretical rigor and empirical grounding, that encourages prescriptive (i.e. 'best practice'), rationale, change approaches. Yet in a business world that is far from stable, the relevance of rational change approaches, such as Lewin's (1947) unfreezing-change-refreezing model, have been questioned (see White, 2000; Biedenbach and Söderholm, 2008). Despite these criticisms, organizations appear to want the certainty that prescriptive change models offer and thus fail to engage with a more evidence-based approach. There are many reasons for this: pressure to adopt perceived 'cutting edge' practices to meet short-term business goals; limited popularity of skepticism, which can enable new forms of evidence to emerge, as well as the politics and power associated with managerial decision making (see Briner and Rousseau, 20I I).

But if prescriptive change approaches are not bringing about the expected outcomes, what other conceptual approaches may be more fruitful? Some authors suggest that a systems approach could be more fruitful. Bunker and Alban (1994, see White, 2000:163) for example, suggest there is a need for a 'whole systems approach' when introducing change aimed at resolving complex problems where it is likely that “... no one entity (e.g. an individual organization) can grapple with the complexities arising". Wentling (2004) too suggests that a 'single initiative' approach (i.e. initiated within a specific organization) is unlikely to be effectual, due to the lack of consideration given to the complex inter-relationships with other structures and systems.

Although the application of systems thinking in the field of management is not new (see White, 2000; Jackson, 2010), there are limited examples of its application to diversity management change (Wentling, 2004; Bassett-Jones et al, 2007). Advocates of a systems approach argue that it is a powerful conceptual framework "... that transcends individual functions and, lines of accountability ... enabling those interested in equality and diversity issues to test some of the rhetoric proffered by large organizations." (Bassett-Jones et al, 2007: 66).

Moreover, Jackson (2010: 138) suggests that a systems approach, particularly when combined with evaluation research, is mutually beneficial: together these approaches "... enrich our understanding of interventions and why they succeed, or fail". There are a number of common features of a systems approach which warrant some discussion given the context of this paper. First, there is the importance of locating and understanding the context within which change is taking place: organizations should be viewed as 'open loop' systems that affect and are affected by external changes (Katz and Kahn, 1969; Morgan, 1986). Second, the importance of feedback loops as a critical means of learning and integration of ideas (Kochen et al, 2003; Jayne and Dipboye,

ISSN: 07 I8-2724. (http://www.jotmi.org)

Journal of Technology Management \& Innovation (c) Universidad Alberto Hurtado, Facultad de Economía y Negocios. 
2004; Jackson, 2010), thus helping reinforce and/or stimulate further change. Cao et al. (2003: 234) emphasize the importance of attending to feedback between different elements (e.g. organizational sub-systems) since " ... change in any one dimension will often have compensatory changes in others", or unintended consequences on another part of the wider system. Feedback from different stakeholders is thus invaluable in building a better understanding of causal and consequential factors (Young, 2009). But as discussed earlier, formal and informal structures can influence the scope, pace and outcomes of diversity change: a point that we return too later in this paper.

\section{Background to the specific diversity change project that has informed this paper}

The study from which our findings are drawn are from an European Social Fund (ESF) project, funded under the European Union's Framework 7 programme, that involved a number of UK-based partner organizations (public and private sector). Faced with declining representation of women in ITEC employment, especially in more skilled roles, this particular ESF change project aimed to “... develop a range of support and intervention tools to help individuals and organizations make progress in ITEC" [I]. The overall project consisted of a number of sub-projects that different partner organizations agreed to lead on, or support in some way. This support came in a number of forms: offering up their organization as a case study; speaking at 'best practice' forums; running career workshops and mentoring programmes, or championing 'return to work' opportunities for women who having been absent from the ITEC labour market for a period of time.

Twenty-four main 'partner organizations' were involved in the project. These were a self-selected group in so far as each organization had agreed to join the project voluntarily. What united these partner organizations was their interest in identifying solutions to the declining representation of women working in the ITEC sector: a situation that many viewed as a business imperative, as the findings will show. All of the individuals representing the partner organizations were already involved in championing other diversity initiatives, thus we feel it appropriate to view them as change agents, even though not all held formal diversity manager roles in their own organizations.

The findings presented below were gathered from semistructured interviews conducted with representatives in eighteen out of the twenty-four partner organizations, during the evaluation phase of the overall project that we had been commissioned to carry out. The roles that participants held in their own organizations varied, but they largely fit Greene and Kirton's (2009) categorization: Organizational
Diversity Specialists (4); Organizational Diversity Champions (5) and Diversity Consultants and Campaigners (8). A further individual, who did not easily fit into these categories, also participated. This individual represented a government department, which had a remit of encouraging partnership working amongst organizations and other institutions to address issues affecting business performance.

Several key questions were explored in the interviews with partner organizations. These included: reasons for their organization's and indeed their own initial engagement in the project; the contribution made by their organization as well as that of other partners; views on the overall impact and the issues and barriers encountered whilst participating on the project and how this may have affected the outcomes, as well as affect involvement in similar projects in the future. Each of the interviews was recorded, transcribed and then subsequently analyzed using Nvivo, with the key codes linked to the main interview questions. From the outset we envisaged a dual-purpose to the evaluation study and participant agreement forms reflected this dual-purpose. In addition to producing a report for the lead partner that addressed the evaluation aims specified above, we felt that the findings could be used in a more reflexive way to produce a more critical paper that exposed the limitations of diversity change initiatives introduced under the auspice of a diversity management approach. The findings presented below reflect this more critical perspective, and have been selected in order to build a case for re-conceptualising the way that change aimed at achieving wider diversity goals (i.e. wider than perhaps fit within an organizational diversity management agenda) might best be enacted. Given this dual-purpose approach we are unable to reveal the specific identity of the partner organizations. Where direct quotes are used in the findings section that follows, we have indicated the category that best represents the role that participants fell into (e.g. Diversity Specialist, Diversity Champion, Diversity consultant/campaigner, or government representative), to provide more context.

Tensions and constraints experienced by 'partner organizations' involved in this ESF funded diversity change project Diversity 'business case' argument: useful for securing initial involvement, but no guarantee of wider commitment.

It was evident from interviews conducted with partner organizations that their participation had had to be justified on 'business case' terms. One participant explained how he had been able to justify his involvement as he could identify a clear link with current business priorities within his organization:

"...the other thing I should have said, and the reason for us focusing on the project management community, is that 
whenever we got involved ... at that moment in time we must have had nearly a hundred outstanding vacancies. I got approached the other day to participate in another strand of diversity [not gender] but I know it's not one of our top priorities for this year, so I just had to politely say 'No'." (Diversity Specialist)

Another spoke of how:

“... on this occasion it ticked two key box for us. One was an activity within that gender stream but the other thing is it was assigned to be a business need which was to help us recruit good people." (Diversity Specialist)

Another participant commented:

"I suppose increasing our profile. We had been aware, from our own profile, that there were diversity, particularly gender, issues and the fact that if we were going to champion these in particularly our schools and university programs, we also needed to raise our own profile in this area." (Diversity consultant/campaigner)

Yet despite the perceived persuasive nature of diversity business case arguments, the use of such arguments did not necessarily gain the support of colleagues when attempting to follow through broader diversity change, initiated outside their specific department. As the following comments indicate, changing business priorities within partner organizations own organization affected their overall involvement in this particular project, despite the initial declared interest in the projects aims:

"I know at one point we were going to do some advertising together [with lead partner] and then we had a lot of people released internally ... and the timing was wrong there so we just had a whole batch of internal people that we needed to look at first before going back to external recruitment again.” (Diversity Champion)

“... it's just that we don't have the fit [to bring in more women returners] because, at the same time, we're downscaling and moving loads of people out." (Diversity Champion

The experiences of these two participants illustrates how triggers for change can emerge from different sources, not necessarily in a planned top-down way as envisaged in a diversity management approach (Özbilgin and Tatli, 2008) and how change initiated in one part of a system can have negative and/or compensatory effects in another (White, 2000). Despite the critical role of senior leaders in endorsing and supporting diversity change (Kochan et al, 2002; Ng, 2008), this does not automatically ensure the support of leaders lower down an organization, as the following experience of one participant indicates: "It's a small group within my team that have got the desire [to bring about diversity change], so I guess it's not sort of mainstream. I do find one or two pockets in the company, where there are senior managers who believe it's a good thing ... the only way l'm going to make it happen is if I work with one of the managers who believes it's a good idea as well, we have a few success stories, and then it happens, and slowly but surely we could move it across the organization." (Diversity Specialist)

Even where there is an espoused commitment to wider diversity change, specific initiatives can still become derailed as a result of external environmental change.The participant representing the government department, pointed out how his department's targets was influenced by wider political change, thus limiting the overall resources that could be made available to support projects like this: "Well, I think it was driven by the target we had, to be honest, and an interest in sectors where we felt there were skills shortages, as part of our history, in a sponsorship role. So it was driven [at that time] really, by the government target on particularly women in ITEC."

\section{Frustrations with inter and intra-organizational collaboration and feedback}

Despite the personal commitment of participants to wider diversity change, their ability to influence change was invariably affected by other factors. The need for better collaboration and feedback amongst partner organizations was raised as an issue by some participants:

"The weakness from our point of view was we just wanted to make sure that if you had organizations with a similar remit, and they all had an interest in getting more women into the sector, or retaining women in the sector, that as much as possible they could collaborate." (Participant representing a government department).

"Rather than working individually, because they [the partner organizations] are all doing bits of work here and there, and not having the sort of collaborative impact that we wanted ... we need to think about, for other similar projects, whether there is a way of getting the different parties to work better together... It needed a better feedback loop." (Diversity consultancy/campaigning organization).

A sense of frustration was particularly evident in the latter of these two comments due to the unwillingness of other 'partner organizations' to fully collaborate at times, even though in theory each 'partner organization' was committed to the overall aims of the project. However given the limitations of generic 'business case' arguments and best practice change, discussed earlier, this frustration is perhaps not so surprising. 
As others point out, collaboration and feedback are key elements of a systems approach, providing important balancing and reinforcing feedback loops (Cavana et al, 2007:2 I3). The experience of 'partner organizations' on this particular ESF funded project reinforces the importance of collaborative working: "I think it has to be all channels and it also has to be linked up thinking as well ... we organized dinners with employers and recruiters looking at skill shortages. And [one of partner organizations] were there, one of the things they do to encourage skills is that managers virtually have to be school governors, because schools are seen as a vital channel for increasing skills ... and it's linking all that up so you get a consistent approach to this area." (Diversity consultancy/campaigning organizations).

Feedback then, as mentioned earlier, is a critical element of a systems approach; it is seen as a key source of learning, helping stimulate further change (Bassett-Jones et al, 2007). But one of the issues we uncovered suggests that those involved in diversity change projects like this need to pay attention to the format of this feedback, to ensure that it is a valuable source of learning. Lengthy reports, that do not offer any new insights, can limit progress as the following comment made at one of the Diversity Forums (one day events organized as part of the overall project as a way of sharing good practice) suggests that these simply encourage 'cloning' of organizational practice: "We have tons and tons of it ["best practice']. A point to make there is whether disseminating best practice is making all companies clones of each other because, from my experience, many of them are doing more or less the same stuff. In some respects we would like someone to come along and reinvent the wheel ... because it will be different and perhaps it will work." (Royal Academy of Engineering, 2007; 75).

Similar concerns have been raised in other forums where business leaders come together to debate change approaches aimed at increasing gender diversity (National Academy of Engineering, 2002; ECWT, 20I I). An Executive in a similar forum spoke of the need find more creative solutions to the problem, suggesting that better collaboration and feedback between organizations was needed. Yet as we discovered, organizations can play the 'commercial sensitivity' card when asked to share specific evaluation data that could shed more light on which practices really do make a difference, rather than simply encouraging 'organizational cloning', as the discussion below illustrates.

\section{Monitoring and evaluation: missed opportunities for wider learning}

Despite the reported importance of diversity 'business case' arguments, gaining access to reliable data on diversity outcomes is difficult. As we discovered, organizations can gain reputational capital from engaging in diversity change projects, but then hide behind issues of 'commercial sensitivity' when asked to make business specific data available which could shed light on which initiatives have been more effective than others. A speaker at one Diversity Forum told us that whilst she was willing to share some organizational specific data with us, this was not something that her organization would be willing to place in the public domain. We recognize, as do others, that evaluating diversity initiatives is problematic and time consuming (Kerston, 2000; Herring, 2009; Simons and Rowland, 20II). Kersten (2000) refers to a lack of consensus on the unit of measurement (e.g. quantitative vs qualitative), as well as difficulties with ensuring that managers at all levels are held accountable for diversity outcomes. One recent report (ECWT, 20II) calls for the adoption of a scorecard approach, with results published on an annual basis. But as several individuals in the partner organizations in this project pointed out, the short timeframe of diversity change projects, particularly those funded by external agencies, is problematic: "With the programme just being 3 years long - just really started to get going and led to wider knowledge.The time cycle for these projects needs to be longer than 3 years. It should have had a further 3 years funding. There have been lots of other projects with a similar theme, but they haven't been built upon [previous ones] ... we need more joined up working and projects especially cross-country that get funded as a proper programme." (Diversity consultancy/campaigning organization). Another explanation for the lack of formal monitoring and reporting of diversity management initiatives is this that this could be considered a form of 'ideological cover' (see Evans, 20I2).

Changes in leadership in particular (internally or externally), is something that is likely to affect the priority and commitment attached to diversity change projects and hence the resources that are made available. New leaders, influenced by 'business case' thinking, are invariably expected to introduce change that brings 'quick wins'; hence the attraction of adopting prescriptive 'best practice' approaches, rather than seeking out more sustainable long-term change solutions.

\section{Discussion and conclusions}

Drawing on a specific case of an ESF funded diversity change project, aimed at addressing the declining representation of women in ITEC, this paper has questioned whether a diversity management approach is effectual when dealing with complex change where the solutions span organizational and institutional boundaries. Despite the concerted efforts of the various partner organizations that supported this particular project, the overall outcomes were mixed. The findings indicate various reasons as to why this was the case. First, progress was thwarted in some cases where the contingent nature of diversity business case arguments got in the way

ISSN: 07 I8-2724. (http://www.jotmi.org)

Journal of Technology Management \& Innovation (c) Universidad Alberto Hurtado, Facultad de Economía y Negocios. 
of participants gaining the commitment of colleagues within their own organization to support the project. Second, although participation on this project helped raise the profile of some participants "... but it has certainly raised our profile within the council and it's certainly raised and put the [diversity] question on the agenda as well" (Diversity champion), the question remains as to what extent the wider learning that emerged from the project permeated organizational boundaries. This comment from one participant sums up the frustrations that she and others experienced "...the trouble was that the sessions, the actual workshops were, as ever, you are preaching to the converted. People who go to them are the people who are already in the space." (Diversity champion). There were concerns too that what gets shared at networking events, tends to fall into the domain of prescriptive best practice, which although perhaps easier for the wider system to ingest, may limit wider diversity aims, hence the reference to 'organizational cloning' made earlier in this paper.Third, difficulties encountered gaining access to data from which judgments can be made about wider diversity outcomes. Related to this point, is the setting of realistic timelines for change when dealing with complex change.

Earlier in this paper we suggested that those engaged in complex change aimed at building a more diverse workforce perhaps need to reframe their view of how such change might be achieved: normative 'business case' assumptions that "diversity is inevitably good, or bad, for businesses", as Kochan et al. (2003:17) suggest, have perhaps run their course and it is timely to consider other conceptual approaches. As discussed earlier, even where managers draw on instrumental diversity 'business case' arguments as a rationale for change, changing priorities in other parts of the wider system (e.g. from another department within their own organization, or from external institutions) can affect their agency in enacting change. Short-term business targets, invariably affect the rhythm, pace and life-span of diversity change projects, where those in positions of power allow this to be the case.

As suggested earlier in this paper an alternative conceptual model that could be more appropriate when attempting to bring about diversity change, is that of a systems approach. Advocates of a systems approach argue that this is particularly useful conceptual model that can be applied when attempting to resolve complex problems, that spans organizational and institutional boundaries, and which arguably no single organization can resolve on its own. As we discovered from the evaluation of this specific diversity project, change is not always initiated in an orderly top-down way, as is the assumption with traditional change models. Instead, change can be initiated from different parts/levels of a wider system: a situation that then makes it more challenging to monitor, track and disseminate outcomes, in a timely way that the wider system can befit from this source of learning.
We are not suggesting that a systems approach should replace a diversity management approach, but rather that it could complement this, providing a conceptual framework that could encourage greater reflexivity amongst different change agents. Of course we recognise that there are potential limitations of a systems approach which require further consideration. First, the underpinning concepts and terminology associated with a systems approach may initially appear alien and off-putting, as might some of the supporting tools and frameworks e.g. 'Open Space technology' and 'Town Hall' style meetings that bring together different stakeholders with an interest in seeking wider change solutions. Monitoring the effects and outcomes of the usage of these tools, particularly in the short-term, could be difficult too given that actions initiated from one part of the wider system (i.e. a specific organization, or institution) can have unexpected consequences (positive or negative) on another part of the wider system. These consequences may not be obvious in the short term (see Jackson (2009) and White (2000) for a more in-depth commentary).

Second, managers may find a systems approach conceptually challenging, as well as operationally difficult, given that they typically work within a system that operates with organizationally defined goals. Although contemporary organizations are supposedly operating with post-bureaucratic structures, with more fluid and facilitative leadership, the reality is that many managers are uncomfortable with managing uncertainty and ambiguity: hence we argue why prescriptive "best practice' approaches are appealing, since they remove the need for reflexivity. Yet without structures and processes that encourage reflexivity, valuable learning opportunities can be missed. Whilst it is acknowledged that Chief Executives play a crucial role in enabling and supporting diversity change, as part of a diversity management approach, it is questionable whether that support alone will secure longterm transformational change. Leaders at the top of an organization may be so far removed that they do not notice where/what change is needed to build a diverse workforce (see Hannah et al, 20I I). We suggest future research could usefully investigate how different change agents engaged in complex diversity change conceptualize such change, what change models inform their practice and why, as well as explore what type of leadership experiences have helped prepare them for managing complex change. Insights from this type of research could usefully inform the way that diversity management is positioned within management education, training and development.

To conclude, we feel that the findings from this evaluation study of a specific ESF funded project offer interesting insights into the weaknesses of conventional change approaches aimed at addressing diversity change within organizations; findings that are particularly important in the 
context of the critical role of women within the transforming IT sector. Our findings demonstrate that diversity change approaches that are contingent on individual business case scenarios, limit the achievement of wider diversity goals. We suggest then that those engaged in diversity change consider adopting a systems approach as an alternative conceptual lens through which to view the problem, thus encouraging the use of alternative change strategies.

\section{Notes}

I.The underpinning research that this paper draws from was part of a larger programme, managed by Equalitec, made possible through funding from the European Social Fund (ESF) under the Equal Programme. The aim of the overall programme was to promote employment and career opportunities in ITEC, particularly to women, and to develop a range of tools and support to help individuals and organizations make progress in ITEC.

\section{References}

ABIR-AM, P.G. (20I0) Gender and Technoscience:A Historical Perspective. Journal of Technology Management \& Innovation, 5(I), I53-165.

ASHLEY, L. (2010) Making a difference? The use (and abuse) of diversity management in the UK's elite law firms. Work, Employment and Society, 24(4), 7 I I-727.

AVDELIDU-FISCHER, N. (20II) The labour market context and its effect on women's participation in independent business and professional networks. In: G. Healy, G. Kirton, and M. Noon (20I I) Equality, Inequalities and Diversity. Contemporary Challenges and Strategies. Palgrave Macmillan, Hampshire:

BASSETT-JONES, N., Brown, R.B. and Cornelius, N. (2007) Delivering Effective Diversity Management Through Effective Structures. Systems Research and Behavioural Science Syst Res. 24, 59-67.

BIEDENBACH,T. and Söderholm,A. (2008) The Challenge of Organizing Change in Hypercompetitive Industries:A Literature Review. Journal of Change Management, 8(2), I23-I45.

BLEIJENBERGH, I., Peters, P. and Poutsma, E. (2010) Diversity management beyond the business case. Equality, Diversity and Inclusion, 29(5), 436-457.

BRINER, R.B. and Rousseau, D.M. (20II) Evidence-Based I-O Psychology: Not There Yet. Industrial and Organizational Psychology, 4(I) March, 2-22.
CAO, G., Clarke, S. and Lehaney, B. (2003) Diversity Management in Organizational Change:Towards a Systemic Framework. Systems Research and Behavioural Science, Sys. Res. $20,23 I-242$.

CAVANA, R.Y., D.M. Boyd, and RJ. Taylor (2007) A Systems Thinking Study of Retention and Recruitment Issues for the New Zealand Army Electronic Technical Trade Group. Systems Research and Behavioural Science. Syst. Res. 24, 201 216.

COCKBURN, C. (200I) Equal opportunities: the short and long agenda. Industrial Relations Journal, 20(3), 213-223.

DASS, P. and Parker, B. (1999) Strategies for managing human resource diversity: From resistance to learning. Academy of Management, 13(2), 68-80.

DICK, P. and Nadin, S. (2006) Reproducing gender inequalities? A critique of realist assumptions underpinning personnel selection research and practice. Journal of Occupational and Organizational Psychology (2006) 79, 48I-498.

DICKENS, L. (1999) Beyond the business case: a threepronged approach to equality action. Human Resource Management Journal, 9(I), 9-19.

DTI (2005) Women in the IT Industry. Towards a Business Case for Diversity. DTI, London.

ECWT (20II) Position Paper on Gender and Technologies: Lining up a Gender Action-Plan for the Digital Agenda (eGEN - ADA 20I I-2015). http://www.asszisztencia.hu/ntit/ down/Position_Paper_ECWT.pdf [Accessed June 2, $20 \mathrm{II}$ ].

E-SKILLS (20I I) Technology Insights 20I I: Summary report. http://www.e-skills.com/technologyinsights20I I. [Accessed February $14,201 \mathrm{I}]$.

EUREOPEAN COMMISSION (2004) Widening Women's Work in Information and Communication Technology, Fondation Travail-Universit】 ASBL. http://www.ftu-namur.org [Accessed June 2, 20II].

EVANS, C. (2012) Recruitment initiatives aimed at increasing the gender diversity within ITEC employment: not so 'gender neutral'. Equality, Diversity and Inclusion:An International Journal (forthcoming, currently available via Earlycite). FAGEN, C., Rubery, J., Grimshaw, D., Smith, M., Hebson, G. and Figueiredo (2005) Gender Mainstreaming in the enlarged European Union: recent developments in the European employment strategy and Social Inclusion Process. Industrial Relations Journal, 36(6), 568-59l. 
FOSTER, C. and Harris, L. (2005) 'Easy to say, Difficult to Do: Diversity Management in Retail', Human Resource Management Journal, I5(3), 4-I7.

Glover, J. and Kirton, G. (2006) Women, Employment and Organizations. Routledge, Oxon.

Glover, J. and Guerrier, Y. (2010) Women in Hybrid Roles in IT Employment: A return to 'Nimble Fingers'? Journal of Technology Management \& Innovation, 5(I), 86-94.

GREENE,A.M. and Kirton, G. (2009) Diversity Management in the UK. Routledge. London, Routledge.

GRIFFITHS, M. and Moore, K. (20I0) 'Disappearing Women': A Study of Women Who Left the UK ICT Sector. Journal of Technology Management \& Innovation, 5(I), 96-I07.

GRIFFITHS, M. and Moore, K. (2006) The Women in ICT (WINICT) Final Report. University of Salford.

HANNAH, S.T., Lord, R. G. and Pearce, C. L. (20II) Leadership and collective requisite complexity. Organizational Psychology Review, I (3), 2I5-238.

HEALY, G., Kirton, G. and Noon, M. (20II) Equality, Inequalities and Diversity. Contemporary Challenges and Strategies. Palgrave Macmillan, Hampshire.

HERRING, C. (2009) Does Diversity Pay?: Race, Gender and the Business Case for Diversity. American Sociological Review, 2009, 74 April, 208-224.

JACKSON, M. C. (2010) 'Reflections on the Development and Contribution of Critical Systems Thinking and Practice', Systems Research and Behavioural Science. Syst. Res., 27, 133-139.

JAYNE, M. E. A. and Dipboye, R.L. (2004) Leveraging Diversity to Improve Business Performance: Research Findings and Recommendations for Organizations. Human Resource Management, Winter 2004, 43(4), 409-424.

JOHNSTON, W. and Packer, A. (1987) Workforce 2000: Work and Workers for the 2 I st Century. The Hudson Institute, New York.

KALEV, A., Dobbin, F. and Kelly, E. (2006) Best Practices or best Guesses? Assessing the Efficacy of Corporate Affirmative Action and Diversity Policies. American Sociological Review, 2006, 7 I August, 589-617.

KATZ, D. and Kahn, R.L. (1969) Common Characteristics of Open Systems. In, F. E. Emery (1969) (Eds) Systems Thinking. Penguin Books, Middlesex.
KERSTEN, A. (2000) Diversity management. Dialogue, dialectics and diversion. Journal of Organizational Change Management, I3(3), 235-248.

KOCHAN, T., Bezrukova, K., Ely, R., Jackson, S. Joshi, A., Jehn, K., Leonard, J., Levine, D. And Thomas D. (2003) The Effects of Diversity on Business Performance: Report on the Diversity Research Network. Human Resource Management, Spring 2003, 42(I), 3-2I.

LANVIN, B. and Passman, P.S. (2008) Building E-skills for the Information Age. The Global Information technology Report 2007-2008. World Economic Forum.

MARVIN, S. and Girling, G. (2000) What is managing diversity and why does it matter? Human Resource Development International, 3(4), 419-433.

NATIONAL ACADEMY of ENGINEERING (2002) Diversity in Engineering. Managing the Workforce of the Future. National Academy Press, Washington.

NG, E. S.W. (2008) Why Organizations Choose to Manage Diversity? Toward a Leadership-Based Theoretical Framework. Human Resource Development Review, 7(I) March, 58-78.

NG, E.S.W. and Burke, R.J. (2005) 'Person-OrganizationFit and the War for Talnet. Does Diversity Management Make a difference? International Journal of HRM, I6(7), I I 95-I2I 0.

ÖZBILGIN, M. F., Beauregard, T.A., Tatli, A. and Bell, M.P. (20II) Work-Life, Diversity and Intersectionality: A Critical Review and Research Agenda. International Journal of Management Review, 13, I77-198.

OSWICK, C. (20II) The social construction of diversity, equality and inclusion. In: Healy, G., Kirton, G. and Noon, M. (20II) Equality, Inequalities and Diversity. Contemporary Challenges and Strategies. Palgrave Macmillan, Hampshire.

ROYAL ACADEMY of ENGINEERING (2007) Equalitec Diversity Forum. Diversity: Changing Corporate Cultures. Summary Report.

SHEN, J., Chanda, A., D'Netto, B. and Monga, M. (2009) Managing diversity through human resource management: an international perspective and conceptual framework. The International Journal of Human Resource Management, 20(2) February, 235-25I.

SYMONS, M. and Rowlands, K.N. (20II) Diversity and its Impact on Organizational Performance:The Influence of Di-

ISSN: 07 I8-2724. (http://www.jotmi.org) 
versity Constructions on Expectations and Outcomes. Journal of Technology Management \& Innovation, 6(3), I72-I83.

TATLI,A. and Özbilgin, M. F. (2009) Understanding Diversity Managers' Role in Organizational Change: Towards a Conceptual Framework. Canadian Journal of Administrative Sciences. DOI: 10.1002/CJAS.I07.

VALENDUC, G. (20I I) Not a job for life? Women's progression, conversion, and dropout in ICT professions. International Journal of Gender, Science and Technology, 3(2), 460482.

WENTLING, R. M. (2004) Factors that assist and barriers that hinder success of diversity initiatives in multinational corporations. Human Resource Development International, $7(2), 165-180$.

WHITE, L. (2000) Changing the "whole system" in the public sector. Journal of Organizational Change Management, 13(2), 162-177.

YOUNG, M. (2009) A meta model of change. Journal of Organizational Change Management, 22(2), 524-548. 